\title{
New non-invasive rapid diagnosis of herpes simplex virus encephalitis by quantitative detection of intrathecal antigen with a chemiluminescence assay
}

\author{
Satoshi Kamei, Tsunao Tetsuka, Toshiaki Takasu, Kazufumi Shimizu
}

\begin{abstract}
A technique for detecting herpes simplex virus (HSV) antigen in CSF by measuring the antigen-antibody complexactivated complement-stimulated chemiluminescence in normal granulocytes was applied to 17 CSF samples from 10 patients with herpes simplex virus encephalitis (HSVE), and 26 samples from 22 patients with a non-HSVE brain illness. All CSF samples taken from the 5 th to the 38th day (including seven from the 5th to the 10th day) of HSVE were positive, whereas those for all non-HSVE samples were negative. This assay required only five hours to yield a result.
\end{abstract}

(F Neurol Neurosurg Psychiatry 1994;57:1112-1114)

Stimulus triggered extracellular production of reactive oxygen species such as superoxide, hydrogen peroxide, and hydroxyl radical is a well known feature of granulocytes. ${ }^{1}$ It has been reported in recent studies ${ }^{2}{ }^{3}$ that a burst of reactive oxygen species, as measured from the luminol dependent chemiluminescence, was induced in phagocytic cells when herpes simplex virus (HSV) type 1 and infected cells were incubated in the presence of immune serum. This study attempted to detect HSV antigen in the CSF by measuring the antigenantibody complex-activated complementstimulated chemiluminescence in normal granulocytes and to use this system of measurement for the early diagnosis of herpes simplex virus encephalitis (HSVE).

\section{Methods}

PATIENTS AND SPECIMENS

The materials were 17 CSF samples from 10 patients with HSVE (10 from six patients with definite HSVE, seven from four patients with probable HSVE), and 26 CSF samples from 22 patients with non-HSVE. Two definite cases of HSVE were proved by the immunohistochemical identification of HSV antigen at necropsy and also with intrathecal
anti-HSV antibody production. ${ }^{4-6}$ The other four were verified from intrathecal anti-HSV antibody production. The patients with probable HSVE showed temporal lesions on cranial CT, periodic synchronous discharges by EEG, and significant increases in their anti-HSV antibody titres in paired CSF samples. The table lists the clinical data for these patients.

The non-HSVE controls were restricted to 22 patients once suspected clinically of having HSVE but who proved retrospectively to have had other diseases. These included tuberculous meningitis (three), fungal meningitis (one), acute disseminated encephalomyelitis (six), encephalopathy associated with systemic lupus erythematosus (three), rubella encephalitis (three), coxsackie encephalitis (one), encephalitis with disseminated herpes zoster infection (three), and acute non-HSV encephalitis (two). Tests were also made on 30 CSF samples from patients with noninfectious neurological diseases of the CNS. These samples were provided by patients with migraine (four), cerebral infarction (eight), amyotrophic lateral sclerosis (three), tension headache (three), spinocerebellar degeneration (five), brain tumour (three), and epilepsy (four).

CHEMILUMINESCENCE ASSAY FOR DETECTION OF HSV ANTIGEN IN CSF

The chemiluminescence of normal granulocytes was measured in two different assays, one including CSF (assay A) and the other including CSF and anti-HSV antibody (assay B). Assay A was thus performed as an assay without anti-HSV antibody. The assay mixture consisted of $0.1 \mathrm{ml}$ CSF sample, $0.7 \mathrm{ml}$ medium containing luminol and $0.2 \mathrm{ml} 50 \%$ diluted normal plasma. Each CSF sample had been stored at $-70^{\circ} \mathrm{C}$ for preservation of its viral antigenicity and inactivation of intrathecal granulocytes. The medium containing luminol was composed of KrebsRinger-phosphate buffer supplemented with $0.5 \mathrm{mM} \mathrm{CaCl}_{2}, 5 \mathrm{mM}$ glucose, and $0.02 \%$ luminol. The plasma was used as complement in the present assay. The mixture was incubated at $37^{\circ} \mathrm{C}$ for 30 minutes. After incubation, an $0.1 \mathrm{ml}$ normal granulocyte 


\begin{tabular}{|c|c|c|c|c|c|c|c|}
\hline $\begin{array}{l}\text { Patient } \\
\text { No }\end{array}$ & Age/sex & $\begin{array}{l}P S D \\
b y \\
E E G\end{array}$ & $\begin{array}{l}\text { Frontotemporal } \\
\text { lesions by } C T \\
\text { andlor MRI }\end{array}$ & $\begin{array}{l}\text { Changes of } A b \\
\text { titres of paired } \\
C S F s \text { (method) }\end{array}$ & $\begin{array}{l}\text { Diagnosis } \\
\text { of HSVE }\end{array}$ & $\begin{array}{l}\text { B/A } \\
\text { ratios }\end{array}$ & $\begin{array}{l}\text { Days after onset of } \\
\text { first symptoms } \\
\text { (days after onset of } \\
\text { neurological symptoms) }\end{array}$ \\
\hline 1 & $37 / M$ & + & + & $\begin{array}{l}\times 4 \rightarrow \times 16 \\
(\mathrm{CF})\end{array}$ & $\begin{array}{l}\text { Pathologically and } \\
\text { serologically definite } \\
\text { (necropsy) }\end{array}$ & $\begin{array}{l}1 \cdot 8 \\
1 \cdot 6\end{array}$ & $\begin{array}{c}6(6) \\
14(14)\end{array}$ \\
\hline 2 & $62 / \mathrm{F}$ & - & + & $\begin{array}{l}\times 1 \rightarrow \times 8 \\
(\mathrm{CF})\end{array}$ & $\begin{array}{l}\text { Pathologically and } \\
\text { serologically definite } \\
\text { (necropsy) }\end{array}$ & $1 \cdot 4$ & $16(13)$ \\
\hline 3 & $17 / \mathrm{M}$ & + & + & $\begin{array}{l}-\overrightarrow{4}+ \\
(\mathrm{c}-\mathrm{ELISA})\end{array}$ & $\begin{array}{l}\text { Serologically definite } \\
\text { (intrathecal } \mathrm{Ab} \text { production) }\end{array}$ & $\begin{array}{l}1 \cdot 7 \\
0 \cdot 8\end{array}$ & $\begin{array}{c}5(3) \\
95(93)\end{array}$ \\
\hline 4 & $30 / \mathrm{M}$ & - & + & $\begin{array}{l}-\rightarrow 2+ \\
(c-E L I S A)\end{array}$ & $\begin{array}{l}\text { Serologically definite } \\
\text { (intrathecal Ab production) }\end{array}$ & $2 \cdot 0$ & $10(10)$ \\
\hline 5 & $66 / M$ & - & + & $\begin{array}{l}-\vec{c}^{3}+ \\
\text { (c-ELISA) }\end{array}$ & $\begin{array}{l}\text { Serologically definite } \\
\text { (intrathecal } \mathrm{Ab} \text { production) }\end{array}$ & $2 \cdot 7$ & $5(5)$ \\
\hline 6 & $19 / M$ & + & + & $\overrightarrow{\text { (c-ELISA) }}$ & $\begin{array}{l}\text { Serologically definite } \\
\text { (intrathecal } \mathrm{Ab} \text { production) }\end{array}$ & $\begin{array}{l}1.9 \\
1 \cdot 8 \\
1 \cdot 4\end{array}$ & $\begin{array}{r}9(4) \\
15(10) \\
25(20)\end{array}$ \\
\hline 7 & $28 / F$ & + & + & $\begin{array}{l}-\overrightarrow{2}+ \\
(\mathrm{s}-\mathrm{ELISA}) \\
\times 1 \rightarrow \times 8 \\
(\mathrm{CF})\end{array}$ & Serologically probable & $\begin{array}{l}1 \cdot 5 \\
1 \cdot 4 \\
0 \cdot 9\end{array}$ & $\begin{array}{c}6(2) \\
17(13) \\
60(56)\end{array}$ \\
\hline 8 & $31 / \mathrm{M}$ & + & + & $\overrightarrow{(s-E L I S A)}$ & Serologically probable & $1 \cdot 9$ & $31(18)$ \\
\hline 9 & $27 / F$ & + & + & $\begin{array}{l}-\rightarrow^{3}+{ }^{+} \\
(s-E I S A)\end{array}$ & Serologically probable & $\begin{array}{l}2 \cdot 7 \\
1 \cdot 0\end{array}$ & $\begin{array}{l}10(9) \\
52(51)\end{array}$ \\
\hline 10 & $20 / \mathrm{M}$ & + & + & $\overrightarrow{(s-E L I S A)}$ & Serologically probable & $1 \cdot 7$ & 38 (14) \\
\hline
\end{tabular}

Positive samples (B/A ratio $\geqslant 1.3$ ) in bold. $A b=$ antibody to $H S V$. PSD = periodic synchronous discharge. $C F=$ complement fixation. c-ELISA = capture enzyme-linked immunosorbent assay; the grading of c-ELISA value in CSF was made as follows; $0 \sim 0.200$ OD values to $(-), 0.201 \sim 0.300$ OD values to $( \pm), 0.301 \sim 0.700$ OD values to $(1+), 0.701 \sim 1.100$ OD values $0 \sim 0.200$ OD values to $(-), 0.201 \sim 0.300$ OD values to $( \pm), 0.301 \sim 0.700$ OD values to $(1+), 0 \cdot 701 \sim 1 \cdot 100$ OD values
to $(2+), 1,101 \sim 1.500$ OD values to $(3+0)$, and $1.501 \sim$ OD values to $(4+)$. s-ELISA $=$ solid enzyme-linked immunosorbent assay; the grading of s-ELISA values was made as follows; $0 \sim 0 \cdot 150$ OD values to $(-), 0 \cdot 151 \sim 0 \cdot 200$ OD values to $( \pm)$, $0.201 \sim 0.700$ OD values to $(1+), 0.701 \sim 1.200$ OD values to $(2+), 1.201 \sim 1.700$ OD values to $(3+)$, and $1.701 \sim$ OD values to $(4+)$. Both c-ELISA and s-ELISA were performed at Special Reference Laboratories, Tokyo, Japan. Intrathecal Ab production: Antibody ratio $=\mathrm{CF}$ antibody titre in serum/CF antibody titre in CSF < 204; the ratios in patients No 1, 2, 6, 7, and 8 were $7 \cdot 8,15 \cdot 6,8,32$, and 32. Antibody index $=C F$ antibody titre in CSF $\times$ albumin concentration in serum/CF antibody titre in serum $\times$ albumin concentration in CSF $>2.5$ The indexes in patients from No 4 to 7 were $4 \cdot 4,6 \cdot 8,7 \cdot 3$, and 1.8. c-ELISA ratio $=c$-ELISA value in CSF/c-ELISA value in serum $\gg 1 .^{6}$ The ratios in patients from No 3 to 6 were $2 \cdot 9,2 \cdot 2,2 \cdot 8$, and $1 \cdot 7$.

suspension was added. The chemiluminescence of the non-stimulated granulocytes at $37^{\circ} \mathrm{C}$ was determined with a luminescence reader (BLR-102, Aloka, Japan). The integrated value of the chemiluminescence for four minutes after supplementation of the normal granulocyte suspension was adopted. Assay B was performed as an assay with antiHSV antibody, which differed from assay A in that $0.1 \mathrm{ml}$ anti-human $\mathrm{HSV}$ antiserum (B-114, Dako, Denmark) was added and the amount of normal plasma was reduced from 0.2 to $0.1 \mathrm{ml}$. The chemiluminescence of the antigen-antibody complex-activated complement-stimulated granulocytes was measured.

The difference in chemiluminescence between the two assays was evaluated as the ratio (the $B / A$ ratio) for each sample. If antigen-antibody complexes were formed and complements were activated by the complexes in assay $B$, the chemiluminescence values would be expected to be higher in assay $B$ than in assay A. It took only five hours to carry out this assay.

\section{EVALUATION OF THE ERROR}

The chemiluminescence values of five CSF samples from five different patients were measured by this assay, three times for each sample consecutively, in order to evaluate the error in the assay.

\section{DETECTION AND MEASUREMENT OF HSV} ANTIGEN IN CSF

Cultured human HSV type 1 in Vero cells was diluted with a control CSF sample, which did not include HSV, to a concentration of $10^{n}(n=0,1,2 \ldots, 6)$ infectious units (plaque forming units (pfu)/ml). The chemiluminescence values of the diluted and control CSF samples as well as 10 samples including 20 to $10^{3} \mathrm{pfu} / \mathrm{ml}$ were measured by assay $\mathbf{B}$.

\section{Results}

EVALUATION OF THE ERROR

The estimated chemiluminescence values for the five CSF samples indicated that the error of the values in this assay was below $\pm 10 \%$.

APPLICATION TO THE DIAGNOSIS OF HSVE

Evaluation of the error in the assay indicated that the error of the $\mathrm{B} / \mathrm{A}$ ratios was within \pm $20 \%$, therefore for safety $B / A$ ratios of 1.3 or more were interpreted as representing positive results. The table lists the estimated B/A ratios. All of the CSF samples taken from the 5 th to the 38th day of HSVE were higher than $1 \cdot 4$. The $B / A$ ratios were higher at an earlier stage than at a later stage in the same patients (cases 1, 3, 6, 7, and 9). The B/A ratios ranged between 0.8 and 1.0 in all of the patients with non-HSVE disease. The difference in frequency of $\mathrm{B} / \mathrm{A}$ ratios above 1.3 between HSVE and non-HSVE was statistically significant $(p<0.01$; Fisher's exact probability test). All CSF samples from the 30 patients with non-infectious neurological diseases of the CNS also gave negative results. 
We further examined the positivity on the 38th day of illness to establish whether this positive result was derived from HSV itself or from other components with HSV antigenicity. The positive CSF sample $(0.4 \mathrm{ml})$, was sedimented at $270000 \times g$ for 60 minutes in an ultracentrifuge. After the centrifugation, $0.1 \mathrm{ml}$ aliquots of the CSF sample were collected separately from the different layers of the sample. The B/A ratios of the different layers were then evaluated. The top layer yielded negative results; the other layers were positive.

\section{DETECTION AND MEASUREMENT OF HSV ANTIGEN IN CSF}

The increase in chemiluminescence values correlated well with that in the infectious units. The value of the sample containing $10^{\circ}$ $\mathrm{pfu} / \mathrm{ml}$ was about double that of the control CSF sample. Between $10^{1}$ and $10^{4} \mathrm{pfu} / \mathrm{ml}$, the regression curve was almost linear. The increase in chemiluminescence values plotted against the common logarithm of the infectious units was linear and statistically significant $\left(y=-25167+22777 \log _{10} \times\right.$ where $\mathrm{y}=$ chemiluminescence value and $\mathrm{x}=$ infectious units; $r=0.993, \mathrm{p}<0.01$ ).

\section{Discussion}

Antiviral chemotherapy at the early stage of HSVE effectively reduces the morbidity and mortality. There is thus a need for early diagnosis. Serological tests provide a potentially useful tool for making a retrospective diagnosis, but they are not useful at the early stage of HSVE. Recently, the detection of HSVDNA in CSF by the polymerase chain reaction has been reported to be a useful diagnostic method at the early stage of HSVE. $^{7-9}$ Such studies showed that the polymerase chain reaction represented a highly sensitive and specific diagnostic test within two to three days after obtaining one CSF sample to identify HSV-DNA. ${ }^{7-9}$ It has been reported, however, that HSV-DNA disappeared before 10 days (days 7 and 9) in some patients with HSVE. ${ }^{810}$ Moreover, the equipment necessary for such detection of viral DNA is extremely expensive.

We have described here another diagnostic method for the early stage of HSVE based on the detection of HSV antigen in the CSF by measurement of chemiluminescence. Our results indicated that it was a useful diagnostic method for HSVE. In particular, it yielded impressive findings for the early diagnosis of HSVE in that all CSF samples taken from the 5 th to the 10th day of HSVE after the onset of first symptoms and the 2nd to the 4th day after onset of neurological symptoms showed positive results. Moreover, these positivities persisted until the 38 th day of HSVE. By contrast all samples from non-HSVE controls and non-infectious neurological controls were negative. This means that our method is highly sensitive and specific. Further, the method required only five hours and is therefore considered to have a high potential as a rapid diagnostic tool.

Further examination of the positive result on the 38th day of HSVE suggested that this positivity was related not only to HSV itself, but also to small viral component proteins with HSV-like antigenicity.

The chemiluminescence values of the samples including HSV correlated with the amounts of infectious units. The increase in chemiluminescence values $v$ the common logarithm of the infectious units of samples ranging from 20 to $10^{3}$ infectious units was significantly linear. These findings suggested that the present method could offer a quantitative means for detecting HSV viral antigen. In fact, a gradual decrease was found in the $\mathrm{B} / \mathrm{A}$ ratios of all five patients repeatedly tested.

In conclusion, our assay based on the generation of chemiluminescence by viral antigen-antibody complex-activated complement-stimulated granulocytes represents a valuable non-invasive, rapid, and even quantitative diagnostic tool for evaluating intrathecal HSV antigen in HSVE.

We are indebted to Dr E J Thompson, Department of Neurochemistry, Institute of Neurology, The National Hospital for Neurology and Neurosurgery, Queen Square, London, UK for valuable comments on the manuscript and Dr Hideki Nakajima, Department of Microbiology, Tokyo Medical and Dental University School of Medicine, Tokyo, for providing cultured HSV type 1. This study was supported by a Grant-in-Aid for General Scientific Research (No 04670501) from the Ministry of Education, Science and Culture, Japan.

1 Babior, BM. Oxygen-dependent microbial killing by phagocytes. N Engl f Med 1978;298:659-68, 721-5. phagocytes. $N$ Engl f Med 1978;298:659-68, 721-5. TW. Dependence on antibody for induction of chemiluminescence in polymorphonuclear leukocytes by herpes simplex virus. Invest Ophathalmol Vis Sci 1985;26: $1236-43$.

3 Weber L, Peterhans E. Stimulation of chemiluminescence in bovine polymorphonuclear leucocytes by virus-antibody complexes and by antibody-coated infected cells. Immunobiology 1983;164:333-42.

4 Kahlon J, Chatteriee S, Lakeman FD, Lee F, Nahmias AJ, Whitley RJ. Detection of antibodies to herpes simplex virus in the cerebrospinal fluid of patients with herpes simplex encephalitis. $\mathcal{F}$ Infect Dis 1987;155:38-44.

5 Klapper PE, Laing I, Longson M. Rapid non-invasive diagnosis of herpes encephalitis. Lancet 1981;ii:607-9.

6 Yoshida A, Tukidate Y, Yamauchi T, Hikichi K, Yoshida A, Tukidate Y, Yamauchi T, Hikichi K, Hatakeno Y. Detection of intrathecal IgG antibody pro-
duction in patients with herpes simplex viral encephalitis. Rinshou to uirus 1986;14:469-75. (In Japanese.)

7 Aurelius E, Johansson B, Sköldenberg B, Staland Å, Forsgren M. Rapid diagnosis of herpes simplex encephalitis by nested polymerase chain reaction assay of cerebrospinal fluid. Lancet 1991;337:189-92.

8 Puchhammer-Stöckl E, Popow-Kraupp T, Heinz FX, Mandl CW, Kunz C. Establishment of PCR for the early diagnosis of herpes simplex encephalitis. $\mathcal{F} \mathrm{Med}$ Virol 1990;32:77-82.

9 Rowley AH, Whitley RJ, Lakeman FD, Wolinsky SM Rapid detection of herpes-simplex-virus DNA in cerebrospinal fluid of patients with herpes simplex encephalitis. Lancet 1990;335:440-1.

10 Pohl-Koppe A, Dahm C, Elgas M, Kühn JE, Braun RW, ter Meulen V. The diagnostic significance of the polymerase chain reaction and isoelectric focusing in herpes simplex virus encephalitis. F Med Virol 1992;36:147-54. 